\title{
Upper body strength and power are associated with shot speed in men's ice hockey
}

\author{
Juraj Bežák and Vladimír Přidal* \\ Faculty of Physical Education and Sports, Comenius University in Bratislava, Bratislava, Slovakia
}

Copyright: (C) 2017 J. Bežák and V. Přidal. This is an open access article licensed under the Creative Commons Attribution License (http://creativecommons.org/licenses/by/4.0/).

\begin{abstract}
Background: Recent studies that addressed shot speed in ice hockey have focused on the relationship between shot speed and variables such as a player's skills or hockey stick construction and its properties. There has been a lack of evidence that considers the relationship between shot speed and player strength, particularly in players at the same skill level. Objective: The aim of this study was to identify the relationship between maximal puck velocity of two shot types (the wrist shot and the slap shot) and players' upper body strength and power. Methods: Twenty male professional and semi-professional ice hockey players (mean age $23.3 \pm 2.4$ years) participated in this study. The puck velocity was measured in five trials of the wrist shot and five trials of the slap shot performed by every subject. All of the shots were performed on ice in a stationary position 11.6 meters in front of an electronic device that measures the speed of the puck. The selected strength and power variables were: muscle power in concentric contraction in the countermovement bench press with $40 \mathrm{~kg}$ and $50 \mathrm{~kg}$ measured with the FiTRODyne Premium device; bench press one-repetition maximum; and grip strength measured by digital hand dynamometer. Results: The correlations between strength/power variables and the puck velocity in the wrist shot and the slap shot ranged between .29-.72 and .16-.62, respectively. Puck velocities produced by wrist shots showed significant correlations with bench press muscle power with $40 \mathrm{~kg}(p=.004)$ and $50 \mathrm{~kg}(p<.001)$; and one-repetition maximum in bench press $(p=.004)$. The slap shot puck velocity was significantly associated with bench press muscle power with $40 \mathrm{~kg}(p=.014)$ and $50 \mathrm{~kg}$ $(p=.004)$. Conclusions: This study provides evidence that there are significant associations between shot speed and upper body strength and power.
\end{abstract}

Keywords: wrist shot, slap shot, muscle power, bench press, grip strength

\section{Introduction}

The game of ice hockey has evolved greatly over the past few years, new rules and new training strategies have been introduced (Haché, 2015). According to evidence provided by sports scientists and scientists in other fields, manufacturers designed lighter and more effective skates, sticks and protective equipment (Haché, 2015; LeGault, 2012). In addition to the rules changes and equipment enhancement, players' size has increased. According to Cook's (2010) Optimum performance pyramid, sports-specific skills represent the top pillar. To be able to fully develop this top pillar, a wide base of appropriate functional movement is needed. Functional movement creates a buffer zone for the middle pillar which represents functional

\footnotetext{
* Address for correspondence: Vladimír Přidal, Department of Sports Kinanthropology, Faculty of Physical Education and Sports, Comenius University in Bratislava, Nábr. arm. gen. L. Svobodu 9, 81469 Bratislava, Slovakia. E-mail: vladimir.pridal@uniba.sk
}

performance. Consequently, the middle pillar creates a buffer zone for the top pillar. The authors of the current study agree on this kind of systematic view of human performance.

Several studies in sports other than ice hockey, investigated the relationship between strength and power and sport-specific skills. Forthomme, Croisier, Ciccarone, Crielaard, and Cloes (2005) found significant correlations between upper body strength and volleyball spike velocity in 19 male volleyball players. Loturco et al. (2016) found significant associations between punching impact and lower and upper body strength and power in elite amateur boxers ( 9 men and 6 women). Marques, van den Tillaar, Vescovi, and González-Badillo (2007) examined the relationship between ball throwing velocity during a 3-step running throw and upper body strength and power in bench press in 14 elite male handball players. Their results indicated a significant relationship between these variables. Similarly, Miyaguchi and Demura (2012) found 
significant correlations between bat swing and upper body strength and power in the bench press in 30 male high-school players. To the best of the authors' knowledge, there is a lack of similar studies performed in the field of ice hockey. The majority of the research done in ice hockey shooting evaluated stick construction or shooting biomechanics, and their effect on shot speed or accuracy. In spite of these studies, it is unclear how much the construction of a hockey stick impacts the player's ability to shoot a puck with high velocity. In fact, studies of Hannon, Michaud-Paquette, Pearsall, and Turcotte (2011), Pearsall, Montgomery, Rothsching, and Turcotte (1999), Lomond, Turcotte, and Pearsall (2007), and Wu et al. (2003) found minimal or no effect of stick stiffness on slap shot puck velocity. Likewise, there was no correlation found between stick stiffness and wrist shot puck velocity. These findings are in contrast with other studies (Grover, Wannop, \& Stefanyshyn, 2013; Kays \& Smith, 2014) in which significant correlations were found between stick stiffness and puck velocity when using slap shots and wrist shots. In research conducted by Worobets, Fairbairn, and Stefanyshyn (2006) they found stick shaft stiffness had an influence on puck velocity only in wrist shots. Based on these studies it is not clear if a player's technique or his strength and body size or the stick is the most influential factor for higher shot speed.

Among all of the shooting techniques in ice hockey, the slap shot produces the highest puck velocity (Hannon et al., 2011; Kays \& Smith, 2014; Worobets et al., 2006; Wu et al., 2003). According to Haché (2002), the very short contact time of stick and puck in the slap shot makes it difficult to shoot accurately. On the other hand, the wrist shot does not produce as high puck velocity as the slap shot, but it is far more accurate owing to the longer blade-puck contact time (Haché, 2002). Haché (2002) reports that the length of sweeping motion in the wrist shot is typically $0.3-1.5 \mathrm{~m}$ long. According to the studies of Emmert (1984) and Pan et al. (1998) the muscle groups involved in the wrist shot at the point of puck release are: wrist extensors and wrist flexors, triceps brachii and lattisimus dorsi. In the slap shot at the point of puck contact the same muscles were activated as in the wrist shot and pectoralis major, anterior deltoid and biceps brachii in addition. The majority of the goals in men's ice hockey games are scored using these two shooting techniques (Saarinen, Mensonen, \& Small, 2006). Because slap shot and wrist shot are the most commonly used shooting techniques in ice hockey (Haché, 2015), only these shooting techniques were included in the current study.

The aim of the study was to investigate the relationship between upper body strength and power and velocity of shooting a puck with two different hockey shots.
The knowledge of how strong this relationship is may assist in designing more effective training programs for shooting enhancement in ice hockey.

\section{Methods}

Testing procedure consisted of two parts. The first part included on-ice measuring of puck velocity of two distinct shooting techniques - the wrist shot (WS) and the slap shot (SLS). The second part was completed in a weight room, where anthropometric measurements and upper body strength and power evaluation were conducted. Each subject performed all of the tests on the same day.

Puck velocity measurements were recorded by sports radar (PR1000-BC, Pocket Radar Inc., Santa Rosa, CA, USA) with measuring accuracy $\pm 2 \mathrm{~km} / \mathrm{h}$. Subjects were allowed to perform five to ten shots prior to testing as a part of warming up. Each subject performed five trials of the wrist shot and then five trials of the slap shot. There was a 30 -second rest between each trial. After completing the wrist shot testing, subjects were given a minimum of 3 minutes rest period before proceeding to the slap shot testing. All of the shot trials were performed from a stationary position. To assure minimal measurement error, the trial was accepted only if the puck was shot into the right half of a net. This setup (Figure 1) was facing the consequences of $1.4 \%$ error of measurement for a puck shot at $85 \mathrm{~km} / \mathrm{h}$ and only $1 \%$ measurement error at $100 \mathrm{~km} / \mathrm{h}$. A shot was considered a successful trial if: the puck went into the target area (right half of a goal with IIHF official dimensions), puck velocity was properly measured, subject was satisfied with the trial and was certain he achieved maximal effort. The best of five trials from each subject was considered in the further evaluations. All of the shots were performed on smooth ice with new and cold (not frozen) pucks with official IIHF dimensions. Subjects were wearing full equipment and were not allowed to switch their sticks during the testing procedure. Subjects used their own regular game sticks. All subjects used composite sticks with taped curved blades. If a player's stick broke, he was asked to repeat all of the trials with his substitute stick. The flex of sticks was not considered in this study.

Weight room testing was completed in the following order: (1) measure subject's weight and height, (2) elbow-to-elbow width measurement with shoulders abducted, (3) dynamic warm up for upper body (about 5 minutes), (4) measure grip strength of right hand (Grip-R) and left hand (Grip-L), (5) measure muscle power in bench press $\left(\mathrm{P}_{\text {mean }}\right)$ with 40 and $50 \mathrm{~kg}$, bench press (BP) one-repetition maximum (1RM). 


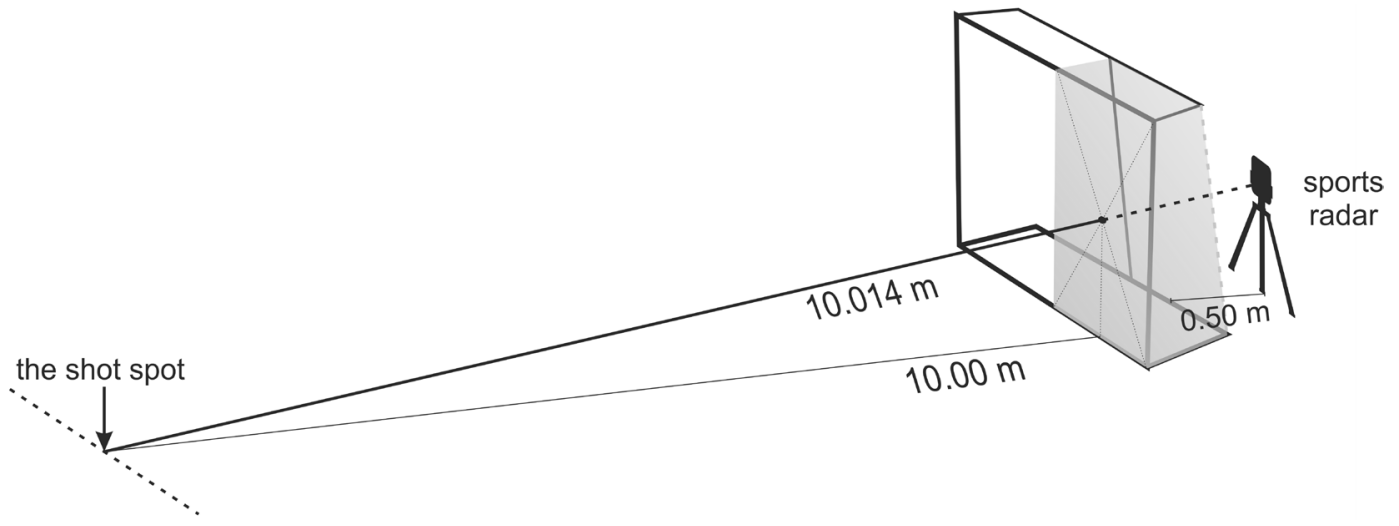

Figure 1. Setup of on-ice testing.

Grip strength was measured with digital hand dynamometer (EH101-37, CAMRY, Harbour City, Hong Kong). Each subject completed two trials with each hand. There was a rest period of 2 minutes between trials with the same hand. The grip strength was measured in the standing position with the shoulder adducted and elbow extended.

Although the bench press does not follow the exact movement pattern of shooting, there are several upper body muscles: wrist extensors, wrist flexors, triceps brachii, anterior deltoid, biceps brachii, pectoralis major (Emmert, 1984; Goodman, Pearce, Nicholes, Gatt, \& Fairweather, 2008; Pan et al., 1998) which are common in shooting and bench-pressing, therefore the authors included the bench press in the current study. Muscle power in concentric contraction in the bench press was measured with the FiTRODyne premium device (FiTRONiC s. r. o, Bratislava, Slovakia) attached to a barbell and connected to a personal computer. FitroDyne measured the speed of the bar, from which muscle power was calculated. The device measures the muscle power with a high degree of reliability (Jennings, Viljoen, Durandt, \& Lambert, 2005). A previous study conducted by Bežák and Přidal (2014) using 14 semi-professional male ice hockey players (age $23.0 \pm 2.7$ years) found the highest correlations between puck velocity and bench press $\mathrm{P}_{\text {mean }}$ with loads of $40 \mathrm{~kg}$ and $50 \mathrm{~kg}$. Since subjects of the current study were strength-trained but not power-trained and estimated average 1RM BP was close to $100 \mathrm{~kg}$, loads of $40 \mathrm{~kg}$ and $50 \mathrm{~kg}$ were included in the study. Subjects were tested in three trials with $40 \mathrm{~kg}$ and in three trials with $50 \mathrm{~kg}$, respectively. There was a rest period of 2 minutes between each trial. Prior testing, each subject had his elbow-to-elbow width measured with shoulders abducted. This width corresponded to bench press grip width for each subject. Subjects placed their hands on the bar that was taped to mark the subjects' elbow-to-elbow width. Subjects were instructed to keep their buttocks, back, and head in contact with the bench and their feet with the floor throughout bench press testing. Each trial started with the command of "unrack the bar", from the researcher. Once the bar was placed above subject's chest with elbows fully extended, the "go" command was given. After this command the subject lowered the bar in a controlled manner for two seconds, touched his chest with the bar and pressed it up with maximal effort until full elbow extension was reached. Subjects were not allowed to bounce the bar off their chest. Neutral wrist position was required throughout bench press to consider the measurement valid.

1RM BP was performed according to Baechle, Earle, and Wathan's (2008) 1RM testing protocol. Subject's 1RM was measured within three to five testing sets. The rest interval between sets was at least 2 minutes, but no more than 3 minutes.

\section{Subjects}

Twenty senior skilled male ice hockey players participated in this study (Table 1). All subjects were professionals or semi-professionals. Sixteen subjects were lefthanded (right hand on the top of the stick) and four subjects were right-handed (left hand on the top of the stick). All subjects were tested during in-season. Each subject was briefed about the scope of the research prior to the testing procedure and submitted written consent to participate in the study. The local review board approved the study and it was performed according to the Declaration of Helsinki.

\section{Statistical analysis}

To assess the relationship between puck velocity and upper body strength and power, Spearman's rank order correlation coefficient (two-tailed) was used. Verbal interpretation of correlation coefficients was done according to Weir (2016) as follows: .00-.19 "very weak"; .20-.39 "weak"; .40-.59 “moderate"; .60-.79 
Table 1

Descriptive statistics of subjects

\begin{tabular}{lc}
\hline Variable & Mean $\pm S D$ \\
\hline Age (years) & $23.3 \pm 2.4$ \\
Body mass $(\mathrm{kg})$ & $84.2 \pm 10.4$ \\
Height $(\mathrm{cm})$ & $183.8 \pm 5.1$ \\
Elbow-to-elbow $(\mathrm{cm})$ & $98.6 \pm 3.9$ \\
WS speed $(\mathrm{km} / \mathrm{h})$ & $105.6 \pm 10.0$ \\
SLS speed $(\mathrm{km} / \mathrm{h})$ & $125.2 \pm 12.6$ \\
1RM BP $(\mathrm{kg})$ & $95.2 \pm 13.8$ \\
Grip- $\mathrm{R}(\mathrm{kg})$ & $65.4 \pm 9.7$ \\
Grip-L $(\mathrm{kg})$ & $62.1 \pm 10.2$ \\
$\mathrm{P}_{\text {mean }} 40 \mathrm{~kg}(\mathrm{~W})$ & $485.4 \pm 50.7$ \\
$\mathrm{P}_{\text {mean }} 50 \mathrm{~kg}(\mathrm{~W})$ & $509.5 \pm 63.3$ \\
\hline
\end{tabular}

Note. $\quad \mathrm{WS}=$ wrist shot; $\mathrm{SLS}=$ slap shot; $1 \mathrm{RM} \mathrm{BP}=$ bench press one repetition maximum; Grip- $\mathrm{R}$ = grip strength of right hand; Grip-L = grip strength of left hand; $\mathrm{P}_{\text {mean }}=$ countermovement bench press muscle power.

"strong"; .80-1.0 "very strong". The reliability coefficients for the shooting tests were quantified using the intraclass correlation coefficient (ICC) using model 1,k. An absolute estimate of the reliability of the puck velocity testing was quantified by means of the standard error of measurement. Statistical significance was accepted at $p<.05$ for all analysis. Descriptive statistics, Spearman's correlation coefficients, and ICC were analyzed by using IBM SPSS Statistics (Version 19 for Windows; IBM Corp., Armonk, NY, USA). To compare the significance of the difference between dependent correlations Hittner, May, and Silver's (2003) modification of Dunn and Clark's $z$ using a back-transformed average Fisher's $Z$ procedure was used. Calculations of $z$ values were conducted using cocor free online software (available at http://comparingcorrelations.org/).

\section{Results}

The main results are presented in Table 2. The mean values for WS and SLS puck velocity were $105.6 \pm 10.0 \mathrm{~km} / \mathrm{h}$ and $125.2 \pm 12.6 \mathrm{~km} / \mathrm{h}$, respectively. Performing intraclass correlation coefficient on all of the trials in WS and SLS resulted in following value: $\operatorname{ICC}(1,5)=.98$ same for both shooting techniques. The standard error of measurement value for the WS puck velocity was $1.76 \mathrm{~km} / \mathrm{h}$ and for the SLS $1.87 \mathrm{~km} / \mathrm{h}$, respectively. The mean 1RM BP and $P_{\text {mean }} 40 \mathrm{~kg}$ and $P_{\text {mean }} 50 \mathrm{~kg}$ were $95.2 \pm 13.8 \mathrm{~kg}$ and $485.4 \pm 50.7 \mathrm{~W}$ and $509.5 \pm 63.3 \mathrm{~W}$, respectively. The load of $40 \mathrm{~kg}$ represented $33-53 \%$ of $1 \mathrm{RM}$ BP and for $50 \mathrm{~kg}$ it was $42-67 \%$ of 1RM BP. Significant correlations were found between WS puck velocity and $\mathrm{P}_{\text {mean }}$ $40 \mathrm{~kg}(r=.61 ; p=.004) ; \mathrm{P}_{\text {mean }} 50 \mathrm{~kg}(r=.72 ; p<.001)$; $1 \mathrm{RMBP}(r=.61 ; p=.004)$ and height $(r=.45 ; p=.046)$. SLS was significantly correlated to $\mathrm{P}_{\text {mean }} 40 \mathrm{~kg}(r=.54$; $p=.014)$ and $\mathrm{P}_{\text {mean }} 50 \mathrm{~kg}(r=.62 ; p=.004)$ only. Subjects' weight and height did not significantly correlate with puck velocity in SLS. Compared to WS, SLS puck velocity showed significantly lower correlations with $1 \mathrm{RM} B \mathrm{BP}$ and the average height of subjects.

\section{Discussion}

Reported puck velocities were within the range of puck velocities stated by Worobets et al. (2006) (wrist shot:

Table 2

Correlations between various variables in the wrist shots and slap shots with peak velocity and significance of difference between these correlations

\begin{tabular}{lllllllll}
\hline & \multicolumn{2}{c}{ WS } & & \multicolumn{2}{c}{ SLS } & & \\
\cline { 2 - 3 } & $r_{\mathrm{s}}$ & $p\left(r_{\mathrm{s}}\right)$ & & $r_{\mathrm{s}}$ & $p\left(r_{\mathrm{s}}\right)$ & & \\
\hline Body mass & .37 & .110 & & .26 & .274 & 0.942 & .173 \\
Height & .45 & .046 & & .24 & .301 & 1.826 & .034 \\
1RM BP & .61 & .004 & & .43 & .059 & 1.734 & .041 \\
Grip-R & .35 & .133 & & .29 & .212 & 0.514 & .307 \\
Grip-L & .29 & .212 & & .16 & .505 & 1.082 & .140 \\
$\mathrm{P}_{\text {mean }} 40 \mathrm{~kg}$ & .61 & .004 & & .54 & .014 & 0.704 & .241 \\
$\mathrm{P}_{\text {mean }} 50 \mathrm{~kg}$ & .72 & $<.001$ & & .62 & .004 & 1.123 & .131 \\
\hline
\end{tabular}

Note. $\quad \mathrm{WS}=$ wrist shot; SLS $=$ slap shot $; r_{s}=$ Spearman's rank correlation coefficient; $p\left(r_{\mathrm{s}}\right)=p$ value of Spearman correlation; $z=z$ value of back-transformed average Fisher's $Z$ procedure; $p(Z)=p$ value of back-transformed Fisher's $Z$ procedure; $1 \mathrm{RM} \mathrm{BP}=$ bench press one repetition maximum; Grip- $\mathrm{R}=$ grip strength of right hand; Grip- $\mathrm{L}=$ grip strength of left hand; $\mathrm{P}_{\text {mean }}=$ countermovement bench press muscle power. 
$96.5 \mathrm{~km} / \mathrm{h}$ in avg. and slap shot: $124.9 \mathrm{~km} / \mathrm{h}$ in avg.) When considering male subjects marked as skilled only, Wu et al. (2003) and Hannon et al. (2011) found lower average puck velocities in their results.

The main finding reported herein is that both WS and SLS puck velocities were strongly associated with subjects' upper body strength and power. However, this is true only for a movement represented in the bench press, because grip strength was not significantly correlated to the shot speed. Both WS and SLS puck velocity showed the highest correlations with muscle power and therefore the muscle power might be a more important parameter than maximal strength. Moreover, SLS, compared to WS, showed lower correlation coefficients with all of the strength and power measures, which may mean that strength and power abilities are more important for higher puck velocities in WS than in SLS.

According to studies of Worobets et al. (2006), Villaseñor, Turcotte, and Pearsall (2006), Lomond et al. (2007), and Kays and Smith (2014) a player's skill and technique are reported as the main factors influencing shot speed, but none of these studies evaluated subjects' strength abilities. Villaseñor et al. (2006) compared slap shot puck velocities of elite and recreational players. This study highlights that it is not the case that elite players hit the puck harder; in fact, both groups applied the same magnitude of force resulting in similar average puck accelerations. The main differences between elite and recreational players were: puck-to-blade contact time achieved; the peak puck velocity; and the blade-puck contact time. Kays and Smith (2014) did not find any effect of inertia or swing speed on slap shot puck velocities among six players of varying skill. Their results showed that the stick-ice contact had a large effect on generating puck velocity. Swings where the blade bounced on the ice, released energy stored in the stick, ending in lower puck velocities. Hannon et al. (2011) investigated shooting with high caliber and low caliber players who had similar grip strength and body mass and found high caliber players performed shots with a greater amount of stick deformation, i.e., shaft bending, and their shots produced higher puck velocities. All of the results listed above came from studies where players of various levels of skills were compared. Consequently, there is a proof of logic behind numerous technique differences. To add more clarity into the relationship between shot speed and different factors, more research with groups of the same level of skills needs to be done.

Wu et al. (2003) found significant correlations between slap/wrist shot puck velocity and 1RM BP; grip strength; and body mass of subjects and no effect of stick stiffness. They stated that both shooting technique (i.e. skill) and body strength are critical factors influencing WS and SLS puck velocity. Contrary to Wu et al. (2003), our present study showed very low correlation coefficients between the shot speed and grip strength. This is an area of research requiring more attention.

The load that maximizes the average mechanical power output $\left(\mathrm{P}_{\max }\right)$ in bench press differs according to the type of training (Baker, Nance, \& Moore, 2001; Castillo et al., 2012;). Castillo et al. (2012), Baker et al. (2001) report that stronger athletes (power-trained) produce $\mathrm{P}_{\text {max }}$ with loads of $40-70 \%$ of $1 \mathrm{RM}$, and conversely normal strength athletes (strength-trained but not power-trained) produce $\mathrm{P}_{\max }$ with loads representing lower percentage of $1 \mathrm{RM}(30-50 \%)$. In the current study bench press loads $40 \mathrm{~kg}$ and $50 \mathrm{~kg}$ represented subjects' $43 \pm 6.2 \%$ of $1 \mathrm{RM} \mathrm{BP}$ and $54 \pm 7.7 \%$ of $1 \mathrm{RM}$ $\mathrm{BP}$, respectively.

The previous study of Pan et al. (1998) examined how strength training affects shooting velocity in ten male collegiate ice hockey players. All players participated in a six-week upper body strength training program. There was no control group. Results of the study showed significant $(p \leq .01)$ increase in the puck speed in the wrist shot and the slap shot by $15.46 \pm 0.59 \mathrm{~km} / \mathrm{h}$ and $16.69 \pm 0.56 \mathrm{~km} / \mathrm{h}$.

There are some experimental limitations of the current study which should be noted. Upper body strength and power were evaluated in two specific movement patterns only. More tests with different movement patterns could add more clarity to strength and power and the shot speed associations. Subjects performed all of the shots in a stationary position, and hence it is unknown if results of this study can be extended to shots performed while skating. There were also advantages of this study. Results might be considered as more sensitive and of higher value since all subjects were highly skilled players. All shots were performed in the ice rink, which ensured game-play like puck friction. Each subject performed the tests with his own stick with to which he was accustomed, so there was no need for subjects to accommodate to an experimental stick.

\section{Conclusions}

Because of the positive associations found between strength abilities and the wrist shot and the slap shot puck velocity, it indicates that stronger and more powerful players will most likely shoot the puck harder. Muscle power was found to be a variable with the highest correlation coefficients in both types of shots. Comparison of correlations showed significantly higher correlation coefficient between the wrist shot puck velocity and bench press 1 RM than between the slap 
shot puck velocity and the same variable. Therefore, we suggest that strength attributes contribute more to the puck velocity upon execution of the wrist shot than upon execution of the slap shot. Additional research is therefore needed. Also, there is a need to assess the effect of different strength and power training programs on the shot speed.

\section{Conflict of interest}

There were no conflicts of interest.

\section{References}

Baechle, T. R., Earle, R. W., \& Wathan, D. (2008). Resistance training. In T. R. Baechle \& R. W. Earle (Eds.), Essentials of strength training and conditioning (3rd ed., pp. 381-412). Champaign, IL: Human Kinetics.

Baker, D., Nance, S., \& Moore, M. (2001). The load that maximizes the average mechanical power output during explosive bench press throws in highly trained athletes. Journal of Strength and Conditioning Research, 15, 20-24.

Bežák, J., \& Přidal, V. (2014). Relationship between shot speed, muscle power and bar speed during bench press in men's ice hockey. In P. Schickhofer \& G. Buzgó (Eds.), Proceedings of the International Scientific Conference Sports, Physical Activity and Health (pp. 54-59). Bratislava, Slovakia: Comenius University in Bratislava.

Castillo, F., Valverde, T., Morales, A., Pérez-Guerra, A., de León, F., \& García-Manso, J. M. (2012). Maximum power, optimal load and optimal power spectrum for power training in upper-body (bench press): A review. Revista Andaluza de Medicina del Deporte, 5, 18-27.

Cook, G. (2010). Movement: Functional movement systems: Screening, assessment and corrective strategies. Aptos, CA: On Target Publications.

Emmert, W. (1984). The slap shot - strength and conditioning program for hockey at Boston college. National Strength and Conditioning Association Journal, 6(2), 4-9.

Forthomme, B., Croisier, J. L., Ciccarone, G., Crielaard, J. M., \& Cloes, M. (2005). Factors correlated with volleyball spike velocity. American Journal of Sports Medicine, 33, 1513-1519.

Goodman, C. A., Pearce, A. J., Nicholes, C. J., Gatt, B. M., \& Fairweather, I. H. (2008). No difference in 1RM strength and muscle activation during the barbell chest press on a stable and unstable surface. Journal of Strength and Conditioning Research, 22, 88-94.

Grover, R., Wannop, B., \& Stefanyshyn, D. (2013). The effect of hockey stick stiffness and energy transfer on puck velocity for wrist and slap shots. Journal of Undergraduate Research in Alberta, 3, 12.

Haché, A. (2002). The physics of hockey. Baltimore, MD: John Hopkins University Press.

Haché, A. (2015). Slap shot science. Baltimore, MD: Johns Hopkins University Press.
Hannon, A., Michaud-Paquette, Y., Pearsall, D. J., \& Turcotte, R. A. (2011). Dynamic strain profile of the ice hockey stick: Comparisons of player calibre and stick shaft stiffness. Sports Engineering, 14, 57-65.

Hittner, J. B., May, K., \& Silver, N. C. (2003). A Monte Carlo evaluation of tests for comparing dependent correlations. Journal of General Psychology, 130, 149-168.

Jennings, C. L., Viljoen, W., Durandt, J., \& Lambert, M. I. (2005). The reliability of the FitroDyne as a measure of muscle power. Journal of Strength and Conditioning Research, 19, 859-863.

Kays, B., \& Smith, L. (2014). Field measurements of ice hockey stick performance and player motion. Procedia Engineering, 72, 563-568.

LeGault, M. (2012). Advanced hockey stick design delivers optimal performance. Retrieved from http://www.compositesworld.com/articles/advanced-hockey-stick-design-delivers-optimal-performance

Lomond, K. T., Turcotte, R. A., \& Pearsall, D. J. (2007). Three-dimensional analysis of blade contact in an ice. Sports Engineering, 10, 87-100.

Loturco, I., Nakamura, F. Y., Artioli, G. G., Kobal, R., Kitamura, K., Cal Abad, C. C., ... Franchini, E. (2016). Strength and power qualities are highly associated with punching impact in elite amateur boxers. Journal of Strength and Conditioning Research, 30, 109-116.

Marques, M. C., van den Tillaar, R., Vescovi, J. D., \& González-Badillo, J. J. (2007). Relationship between throwing velocity, muscle power, and bar velocity during bench press in elite handball players. International Journal of Sports Physiology and Performance, 2, 414-422.

Miyaguchi, K., \& Demura, S. (2012). Relationship between upper-body strength and bat swing speed in high school baseball players. Journal of Strength and Conditioning Research, 26, 1786-1791.

Pan, W. T., Campbell, D. C., Richards, J. G., Bartolozzi, A. R., Ciccotti, M. G., Snyder-Mackler, L., \& Waninger, K. N. (1998). Effect of upper extremity strength training on puck speed in collegiate ice hockey players. Medicine \& Science in Sports \& Exercise, 30(Suppl. 5), 35.

Pearsall, D., Montgomery, D., Rothsching, N., \& Turcotte, R. (1999). The influence of stick stiffness on the performance of ice hockey slap shots. Sports Engineering, 2, 3-11.

Saarinen, M., Mensonen, J., \& Small, D. (2006). Goal analysis. Retrieved from http://www.iihce.fi/DesktopModules/A_ Repository/Download.ashx?id=27

Villaseñor, A., Turcotte, R. A., \& Pearsall, D. J. (2006). Recoil effect of the ice hockey stick during a slap shot. Journal of Applied Biomechanics, 22, 200-209.

Weir, I. (2016). Spearman's rank correlation - introduction. Retrieved from http://www.statstutor.ac.uk/resources/ uploaded/spearmans.pdf

Worobets, J. T., Fairbairn, J. C., \& Stefanyshyn, D. J. (2006). The influence of shaft stiffness on potential energy and puck speed during wrist and slap shots in ice hockey. Sports Engineering, 9, 191-200.

Wu, T. C., Pearsall, D., Hodges, A., Turcotte, R. A., Lefebvre, R., \& Montgomery, D. (2003). The performance of the ice hockey slap and wrist shots: The effects of stick construction and player skill. Sports Engineering, 6, 31-39. 